\title{
Inadvertent Intrathecal Injection of Atracurium: A Case Report
}

Kuvaki B*, Özbilgin Ş and Ataseven B Küçüik Department of Anesthesiology and Intensive Care, Dokuz Eylül University Faculty of Medicine, Izmir, Turkey *Correspondling author: Kuvaki B, Department of Anesthesiology and Intensive Care, Dokuz Eylül University Faculty of Medicine, Izmir, Turkey

Received: June 22, 2017; Accepted: J uly 07, 2017; Published: July 14, 2017

\begin{abstract}
Drug administration errors are a matter of increasing concern in anesthesiology. Errors usually pertain to the type of drug administered, dosage, rate of administration, or site of administration. A 56-year-old woman weighing $62 \mathrm{~kg}$ with urinary incontinence was scheduled for a Transobturator Tape (TOT) operation. We decided to perform spinal anesthesia for her operation. We describe the injection of atracurium, a Neuromuscular Blocking (NMB) agent, instead of hyperbaric bupivacaine for spinal anesthesia. The effects of NMB agents in Cerebrospinal Fluid (CSF) are unknown and reports differ, but observations suggest that NMB agents are inert when injected into CSF. Fortunately this patient experienced no adverse effect from this administration error.
\end{abstract}

Keywords: Spinal anesthesia; Atracurium; Administration error

\section{Introduction}

Spinal anesthesia is commonly used in surgical procedures. Since its invention accidents have occurred, including the injection of incorrect pharmaceuticals not intended for intrathecal administration. A wide variety of medication errors in spinal anesthesia have been reported.

Errors usually pertain to the type of drug administered, dosage, rate of administration, or site of administration. One of the most serious errors, comprising a significant subset of these events, involves drug administration. Approximately $15 \%$ of all anesthetic critical incidents involve drug administration errors, which can include administration of the incorrect drug, dosage, route, speed of delivery, or any combination of those errors.

Most wrong drug incidents may be attributed to 'syringe swaps' or ampoule errors; both involve accidental interchanging of the intended container with another, resulting in the wrong drug being administered. Over half of the drug errors of both types involved ampoules or syringes of similar size, label, and colour. Other contributing factors include errors involving drug location, labelling, and assisting personnel and equipment use.

'Fatigue' and 'inattention' are also major factors in wrong drug cases. Also the ampoule of atracurium and heavy bupivacaine had similar colours at the labels. We describe the injection of atracurium, a Neuromuscular Blocking (NMB) agent, instead of hyperbaric bupivacaine for spinal anesthesia. The effects of NMB agents in Cerebrospinal Fluid (CSF) are unknown and reports differ, but observations suggest that NMB agents are inert when injected into CSF [1].

\section{Case Presentation}

A 56-year-old woman weighing $62 \mathrm{~kg}$ with urinary incontinence was scheduled for a Transobturator Tape (TOT) operation. Her medical history included type II diabetes under control with oral hypoglycemic agents, hypertension, gastro esophageal reflux and scleroderma. Physical examination and biochemical tests were normal. We decided to perform spinal anesthesia for her operation. Prior to the procedure, $1 \mathrm{mg}$ midazolam was injected intravenously and $1000 \mathrm{~mL}$ crystalloid fluid administration was begun. Electrocardiogram (ECG), noninvasive blood pressure, heart rate $(\mathrm{HR})$, and peripheral oxygen saturation $\left(\mathrm{SpO}_{2}\right)$ were monitored (Dräger Zeus Infinity Empowered, Drägerwerk AG \& Co, Lübeck, Germany). Basal measurements of Mean Arterial Pressure (MAP) and HR were $92 \mathrm{mmHg}$ and 57 beats per minute (bpm), respectively.

Just prior to lumbar puncture, the anesthesiologist drew $2.0 \mathrm{~mL}$ of hyperbaric bupivacaine and $25 \mu \mathrm{g}$ fentanyl into a $5 \mathrm{~mL}$ syringe from an open drug ampoule held by the nurse anesthetist. With the patient in a seated position, aseptic lumbar puncture at the L3-4 interspace using a 25G Quicker spinal needle was successful on the first attempt. The CSF observed confirmed the correct position; the drug mixture was injected into the subarachnoid space.

After injection, the patient was placed in a supine position. The patient was comfortable and vital signs were normal. After five minutes the level of subarachnoid blockade was assessed using the pinprick test; no analgesia or temperature loss effect was detected. Effects remained undetected after an additional five-minute interval. While discussing the possible reasons, empty ampoules were examined. A broken atracurium ampoule, and no open hyperbaric bupivacaine ampoule, was discovered. The nurse anesthetist had opened the incorrect ampoule. As a result, $20 \mathrm{mg}$ atracurium were mistakenly administered into the patient's subarachnoid space.

The patient was comfortable, with no hemodynamic instability. Results of the neurologic examination, including force and tonicity of peripheral extremity muscles, were normal. Pinprick and temperature tests and spontaneous movements were also normal.

In the absence of any clinical signs or symptoms of distress, we decided to induce general anesthesia for the operation. General
Austin J Anesthesia and Analgesia - Volume 5 Issue 1 - 2017 ISSN : 2381-893X | www.austinpublishing group.com Kuvaki et al. @ All rights are reserved
Citation: Kuvaki B, Özbilgin Ş and Küçük AB. Inadvertent Intrathecal Injection of Atracurium: A Case Report. Austin J Anesthesia and Analgesia. 2017; 5(1): 1055 
anesthesia was maintained with remifentanyl $(0.2 \mu \mathrm{g} / \mathrm{kg} / \mathrm{min})$ and sevoflurane. The intraoperative period was uncomplicated and the patient's vital signs remained stable. After a total operation time of 45 minutes, the patient was extubated uneventfully and was observed continuously in the recovery room. Her ability to breathe, lift her head, protrude her tongue, and bend her legs was evaluated. The neurologic examination was performed again at one, two, four and eight hours, and findings were ordinary. Thereafter the patient was transferred to the gynecology ward.

The following day the patient complained of weakness and sensorial deficit of her left lower limb. She was immediately evaluated by neurologists, who reported diabetic neuropathy. The patient was discharged from the hospital two days later, with instructions to follow up with a neurologic examination and electromyography results. One week after discharge she was evaluated again; all results were normal.

We have obtained informed consent for this case report.

\section{Discussion}

In this case, we inadvertently administered atracurium instead of hyperbaric bupivacaine for spinal anesthesia. The 'wrong drug' is the most common type of drug administration error; one survey revealed anesthesiologists have made this type of error at least once in their careers [2]. A separate, prospective study in which anesthesia providers were asked to voluntarily report whether a medication error had occurred during their anesthetic care revealed one incident per 133 cases [3].

Besides ampoule errors and syringe swaps, 'Fatigue' and 'inattention' are also major factors in wrong drug cases. Also the ampoule of atracurium and heavy bupivacaine had similar colours at the labels. In a study performed by the Australian Incident Monitoring Study (AIMS), 'fatigue' was a major factor in $10 \%$ of reported cases, while 'inattention' was cited in nearly $50 \%$ [4]. We believe fatigue and inattention were important issues in this case. The responsible senior anesthetist had to attend a meeting as the patient arrived in the OR. Consequently, her attention to detail was affected. Previously, she had controlled the drugs held by the nurse anesthetist. During this case she delegated that step, both to save time and because she trusted the nurse anesthetist and the resident who had prepared the anesthesia equipment.

Direct or accidental brain injections of NMB agents including gallamine or tubocurarine have been associated with convulsions and neuronal damage $[5,6]$. Evidence shows that NMB causes excitement and seizures when administered into the CNS [7]. Accidental injection of small doses of gallamine or pancuronium into CSF caused autonomic dysfunction and weakness in humans [8,9]. Laudanosine, a metabolite of atracurium, may contribute to seizure activity due to high doses of atracurium injection intravenously [10].

Several studies suggest that NMB agents introduced into the CNS are pharmacologically active. Autonomic dysfunction, weakness, neuromuscular blockade, neuronal death, and seizures have been observed [7,8,11], Salihoglu et al, described generalized hypotonia, tachycardia, hypotension, diplopia, and discomfort after inadvertent subarachnoid injection of atracurium [11]. The hemodynamic changes were thought to be caused by direct histamine releasing actions related to the injection; duration was short and supported this hypothesis. However, a similar case reported no adverse reactions [12].

Peduto et al [9], suggested that intrathecal injection of hyperbaric $1 \%$ bupivacaine solution shortly after the accidental injection of an NMB could limit NMB diffusion [9]. However, bupivacaine treatment could be harmful - any increase in length of time an NMB agent remains in the CSF may prolong neural effects. Atracurium is degraded through Hoffman elimination. $\mathrm{pH}$ and temperature are very important; prevention of hypothermia and use of a blanket may speed degradation.

Whatever type of anesthesia is administered, threatining consequences for patient safety may occur during and after anesthesia. These may be patient related, anesthesia or surgery related or due to environmental factors [13]. Evaluating patient safety does not merely comprise examining results; at the same time it requires careful attention to risks and errors during the anesthesia care process. "Medication error" and "patient transfer" processes carry special risk. The technical and non-technical skills related to human factors of professionals dealing with anesthesia are not the only factors affecting patient safety. Raising the level of knowledge of various stakeholders in the community and ensuring necessary support from competent political authorities are at least as important. This especially includes financial support for various interventions designed to increase patient safety. Within this scope, in June 2010 they accepted the "Helsinki Declaration on Patient Safety in Anesthesiology".

Anesthesiology is one of the most important parts in terms of patient safety and secure healthcare compared with other medical sections [13]. Poor labeling of ampoules and vials was identified as another important cause of drug errors. Strategies described to prevent such errors include improved labeling with clear fonts that emphasize the generic name rather than the proprietary name [14], using a two-person check when drawing up drugs, and the introduction of bar-coded ampoules with a computer that speaks the name of the drug after it has been scanned before being drawn up. Nwasor et al. Suggested Selection of appropriate drugs by the anesthetists, provision of adequate manpower (anesthetists), and training and retraining of those already on staff. These aspects of minimizing errors drug administration are necessary in order to maintain a high level of safety. Reduction in the incidence of medication errors is an important aspect of patient safety, and vigilance remains the watchword in the safe conduct of anesthesia [15].

However, the cause of the problem was a medical error. Despite best efforts, the increased use of technology and high standards of monitoring in anesthesia and critical care, medication errors continue to occur even at the best centres worldwide. Lack of experience, inadequate familiarity with equipment, poor communication, inattention, and fatigue are the major risk factors for these errors [14]. As suggested by Jensen et al. The label on the ampoule or syringe should be read carefully before administration. There should be a consistent method for the arrangement of medications in the operating room, and labels should be double-checked [16]. Adherence to such recommendations will certainly decrease the number of medical errors that occur. 


\section{Compliance with Ethical Standards}

\section{Ethical approval}

All procedures performed in this case report involving human participant were in accordance with the ethical standards of the institutional and/or national research committee and with the 1964 Helsinki declaration and its later amendments or comparable ethical standards.

\section{Informed consent}

Written informed consent was obtained from the patient for publication of this Case Report. A copy of the written consent is available for review by the Editor-in-Chief of this journal.

\section{References}

1. Szenohradszky J, Trevor AJ, Bickler P, Caldwell JE, Sharma ML, Rampil IJ, et al. Central nervous system effects of intrathecal muscle relaxants in rats. Anesth Analg. 1993; 76: 1304-1309.

2. Smellie GD, Lees NW, Smith EM. Drug recognition by nurses and anesthetists. Anaesthesia. 1982; 37: 206-208.

3. Webster CS, Merry AF, Larsson L, McGrath KA, Weller J. The frequency and nature of drug administration error during anaesthesia. Anaesth Intensive Care. 2001; 29: 494-500.

4. Webb RK, Currie M, Morgan CA, Williamson JA, Mackay P, Russell WJ, et al. The Australian Incident Monitoring Study: an analysis of 2000 incident reports. Anaesth Intensive Care. 1993; 21: 520-528.

5. Matteo RS, Pua EK, Khambatta HJ, Spector S. Cerebrospinal fluid levels of d-tubocurarine in man. Anesthesiology. 1977; 46: 396-399.

6. Goonewardene TW, Sentheshanmuganathan S, Kamalanathan S, Kanagasunderam R. Accidental subarachnoid injection of gallamine. A case report. Br J Anaesth.1975; 47: 889-893.
7. Scheepstra GL, Vree TB, Crul JF, van de Pol F, Reekers-Ketting J. Convulsive effects and pharmacokinetics of laudanosine in the rat. Eur $\mathrm{J}$ Anaesthesiol. 1986; 3: 371-383.

8. Mesry S, Baradaran J. Accidental intrathecal injection of gallamine trietiodide. Anaesthesia. 1974; 29: 301-304

9. Peduto VA, Gungui P, Di Martino MR, Napoleone M. Accidental subarachnoid injection of pancuronium. Anesth Analg. 1989; 69: 516-517.

10. Cardone C, Szenohradszky J, Yost S, Bickler PE. Activation of brain acetylcholine receptors by neuromuscular blocking drugs. A possible mechanism of neurotoxicity. Anesthesiology. 1994; 80: 1155-1161.

11. Salihoglu Z, Demiroluk S, Kose Y. Accidental subarachnoid injection of atracurium: a case report. J Anesth. 2002; 16: 72-74.

12. Zirak N, Soltani G, Ghomian N, Hasanpour MR, Mashayekhi Z. Inadvertent intrathecal injection of atracurium. Saudi J Anaesth. 2012; 5: 223-225.

13. Mellin-Olsen J, Staender S, Whitaker DK, Smith AF. The Helsinki Declaration on Patient Safety in Anaesthesiology. Eur J Anaesthesiol. 2010; 27: 592-597.

14. Cooper L, DiGiovanni N, Schultz L, Taylor RN, Nossaman B. Human factors contributing to medication errors in anaesthesia practice. ASA. 2009: A614.

15. Nwasor EO, Sule ST, Mshelia DB. Audit of medication errors by anesthetists in North Western Nigeria. Niger J Clin Pract. 2014; 17: 226-231.

16. Jenson LS, Merry AF, Webster CS, Weller J, Larson L. Evidence based strategies for preventing drug administration errors during anaesthesia. Anaesthesia. 2004; 59: 493-504.

17. Jannicke Mellin-Olsen, Sven Staender, David K. Whitaker and Andrew F. The Helsinki Declaration on Patient Safety in Anaesthesiology. SmithEur J Anaesthesiol. 2010; 27: 592-597.
Austin J Anesthesia and Analgesia - Volume 5 Issue 1 - 2017 ISSN : 2381-893X | www.austinpublishing group.com Kuvaki et al. () All rights are reserved
Citation: Kuvaki B, Özbilgin S and Küçük AB. Inadvertent Intrathecal Injection of Atracurium: A Case Report. Austin J Anesthesia and Analgesia. 2017; 5(1): 1055. 